\title{
VIDA A CRÉDITO E CONSUMISMO: A PROCRASTINAÇÃO DE CABEÇA PARA BAIXO
}

\author{
Cícero Josinaldo da Silva Oliveira ${ }^{1}$ \\ Universidade Federal do Recôncavo da Bahia (UFRB) \\ (D) https://orcid.org/0000-0002-4517-8510
}

\begin{abstract}
RESUMO:
Apesar das notáveis mudanças operadas sobre o mundo do trabalho, a mais radical das transformações já registradas no capitalismo passa antes de tudo pela ênfase inusitada sobre a capacidade que os rendimentos desta atividade asseguram: a capacidade de consumo. Seguindo as reflexões de Richard Sennett e Zygmund Bauman, registramos nos termos de uma "revolução copernicana do capitalismo" a virada extraordinária que, no interior deste sistema econômico moderno, substitui o imperativo da satisfação adiada e as realizações a longo prazo (que são aspectos fundamentais da "fase heroica" do capitalismo segundo Marx Weber), pelo princípio consumista da satisfação imediata e renovada, assim como a frugalidade pela prodigalidade, o ascetismo pelo gasto dispendioso, as práticas compulsórias de poupança e postergação pelo desejo incontido de felicidade aqui e agora perseguido via consumo. Com o presente texto propomos portanto uma análise da inflexão de valores que marca o recente capitalismo de economia flexível e de práticas consumistas, no confronto com a antiga "ética da procrastinação" de que fala Weber.
\end{abstract}

PALAVRAS-CHAVE: Novo capitalismo; Trabalho; Procrastinação; Satisfação imediata; Consumismo.

\section{LIFE ON CREDIT AND CONSUMERISM: A REVERSAL IN PROCRASTINATION}

\footnotetext{
ABSTRACT:

Despite the remarkable changes operated on the world of work, the most radical changes ever recorded in capitalism goes first of all the unusual emphasis on the ability of the proceeds from this activity ensure: a consumption capacity. Following the reflections of Richard Sennett and

${ }^{1}$ Doutor em Filosofia pela Pontifícia Universidade Católica do Rio de Janeiro (PUC-RIO), Rio de Janeiro - Brasil. Professor de filosofia da Universidade Federal do Recôncavo da Bahia (UFRB), Bahia - Brasil. E-mail: cicerojosinaldo@gmail.com
} 
Zygmund Bauman, recorded in terms of a "Copernican revolution of capitalism" the extraordinary turn that inside this modern economic system, replacing the imperative of deferred satisfaction and long-term achievements (which are fundamental aspects the "heroic phase" of capitalism Marx Weber), the consumer principle of immediate and great satisfaction, as well as frugality by profligacy, asceticism by costly expense, savings compulsory practice and postponement by the unrestrained desire for happiness here and now hunted via consumption. With this text we propose therefore an analysis of the inflection values marking the late capitalism of flexible economy and consumerist practices, compared to the old "ethics of procrastination" according to Weber.

KEYWORDS: New capitalism; Work, Procrastination; Immediate satisfaction; Consumerism.

\section{Um novo trabalho para um novo capitalismo}

Quando Richard Sennett, em A corrosão do caráter, examinou as consequências pessoais do trabalho de curto prazo e flexível, um novo tipo de trabalho que é símbolo dos nossos tempos, admitiu de saída uma radical inflexão na ordem econômica que ele registrou com a expressão "novo capitalismo". Denominação que resguarda uma destacada afinidade com o modo como o sistema econômico atual se auto define. Trata-se de um "capitalismo flexível" para o qual o conceito de trabalho em exame converge. Flexibilidade é a marca de um capitalismo que agora ataca as estruturas estáveis da operacionalidade, burocracia e males de sua rotina pregressas. É este o novo capitalismo que demanda um mercado de mão de obra desregulamentado e trabalhadores flexíveis ou adaptáveis às circunstâncias, a saber, pessoas de qualidades flutuantes, dispostas a assumir riscos contínuos, abertas a mudanças e projetos de curto prazo e sempre menos apoiadas em leis, medidas formais e outros mecanismos de estabilidade que ajudaram a plasmar a imagem do trabalho como carreira ${ }^{2}$.

\footnotetext{
2 "O sistema empregatício surgido no último século a partir de graves crises e conflitos sociais e políticos se apoia em padronizações intensivas em todas as suas dimensões básicas: do contrato de trabalho, do local de trabalho e da jornada de trabalho. A disposição da força de trabalho segue em sua configuração jurídica modelos contratuais que, em certa medida, são negociados em margens percentuais para setores e categorias profissionais inteiras. Tornou-se óbvio que o trabalho seja realizado de forma espacialmente concentrada, em (grandes) organizações fabris. O sistema empregatício também se assentava - com algumas exceções - até meados dos anos setenta na regra geral do 'trabalho vitalício de jornada integral' com parâmetro de organização temporal para o planejamento e mobilização de mão de obra na empresa, mas também para definir as circunstâncias biográficas. Esse sistema permite - em princípio - traçar claras delimitações entre trabalho e ócio, passíveis de fixação no espaço e no tempo, mas também contornos sociais e jurídicos distinguindo desemprego e emprego. Em função das atuais e iminentes
} 
A qualidade de ser flexível, politicamente exigida para o trabalho do novo capitalismo, refere-se à necessidade, economicamente autorreferida, de convertê-lo em uma variável ínfima o bastante para ser desconsiderada na trama de uma economia marcada pela mobilidade global do capital à procura de pastos verdes. A flexibilidade é o dispositivo que neutraliza as incômodas variações e os custos com que os investidores teriam de lidar, no caso de não interporem medidas à antiga "rigidez" das regras com as quais o Estado social arbitrava as condições do mercado de trabalho. De forma que o índice e a eficiência da flexibilidade do trabalho, num cenário econômico global em que a própria condição de arbítrio político foi de algum modo subvertida, podem ser aferidas pelo vigor com que os investidores controlam a conduta da mão de obra e expropriam seu poder de resistência.

Flexibilidade é a qualidade do que é elástico, arqueável, do que se dobra ou se curva sem opor resistência, do que se acomoda às circunstâncias, do que é facilmente influenciável e dócil, e que possui disposição para condições e atividades diversas. Em Vidas desperdiçadas Bauman sublinhou que quando os políticos pedem ao eleitores que sejam flexíveis, querem na verdade "que se preparem para ter mais insegurança no futuro e busquem individualmente suas próprias soluções individuais para problemas socialmente constituídos" (BAUMAN, 2004a, p. 112). Sem meias palavras, flexibilidade é algo que aponta para um conjunto de circunlocuções que escamoteiam uma nova modalidade de controle de difícil leitura. A desqualificação sistemática da rotina e da burocracia rígida, mas também a ênfase sobre a adaptabilidade da mão de obra às circunstâncias, que são o mote com que a economia flexível alega oferecer liberdade aos indivíduos, abole as antigas regras do trabalho mas ao mesmo tempo inaugura e põe em funcionamento novos dispositivos de opressão.

É verdade que a velha disciplina de trabalho, com sua austeridade e disciplina marcantes, impunha fardos pesados que oprimiam sobremaneira o trabalhador. Weber os reconhece quando admite que dar provas de valor individual na forma de "ascetismo leigo" tendia para práticas autodestrutivas, que o compulsório adiamento da satisfação encobre uma fraude, pois uma vez que a aplicação aos esforços de trabalho e poupança nunca se consumam, também as recompensas prometidas jamais chegam.

Seja como for, não se deve esquecer que os valores do trabalho radicados na ética da satisfação adiada modelaram um estado mental, um temperamento ou um conjunto de traços morais e psicológicos a partir dos quais os indivíduos orientaram e modelaram suas vidas segundo projetos de longo prazo. Este, como sabemos, é o pano de fundo que desaparece

ondas de racionalização, esse sistema padronizado de pleno empego começa a debilitar e a carcomer, através de flexibilizações a partir das margens, seus três pilares de sustentação - direito do trabalho, local de trabalho, jornada de trabalho. Com isso, as fronteiras entre trabalho e ócio se tornam fluidas. Formas flexíveis e plurais de subemprego se difundem." (BECK, 2010, p. 207. Grifos nossos) 
justamente com a ética da procrastinação, cujo processo de desgaste é um fenômeno coevo ao advento do trabalho flexível.

A noção protestante de vocação que por um longo tempo orientou o mundo do trabalho era empregada, como o próprio Weber afirmou, "no sentido de um plano de vida, de uma determinada área de trabalho" (WEBER, 2001, p. 43), enfim, de uma carreira. Uma carreia que o capitalismo flexível se mostra realmente decidido a inviabilizar e, assim, a marcar o trabalho com o signo da eventualidade, do risco e da desorientação, refratárias a qualquer forma de planejamento. Trata-se neste caso de uma nova forma de trabalho cuja particularidade é não comportar projetos para organização de longo prazo das histórias de vida. Com entusiasmo ou a contragosto os indivíduos ingressam agora em um mercado de trabalho que é cada vez menos receptivo ao planejamento estratégico de suas trajetórias profissionais. "O futuro profissional após a formação universitária não se perde no caminho, mas se torna imprevisível e incalculável. Consequentemente, o planeamento de longo prazo é, com frequência, substituído pela dedicação às possibilidades passageiras" (BECK, 2010, p. 227)

"O homem-poupança", analisado por Weber, é também o homem que pelo trabalho e de forma extremada "vive o futuro em cada parcela do presente" (Lima, 2011, p. 59), que portanto e em última análise planeja a vida a partir das experiências com instituições estáveis com que ele modela a si mesmo. A gratificação era postergada no presente em vista de metas de longo prazo. Por muito tempo na história do capitalismo o trabalho foi definido segundo uma afinidade com o futuro (carreira), para o qual o trabalhador se voltava no sentido de organização de um plano de vida. Este aspecto do trabalho ancorado na estabilidade, numa certa confiança nas instituições humanas que nos permite o planejamento da vida, está chegado ao fim nas instituições de ponta do capitalismo flexível. De maneira inversa o trabalho agora se define como errático, episódico e arriscado. Integra o rol dos dispositivos para uma deliberada reorganização do tempo institucional, que na economia do novo capitalismo flexível e mutante é o tempo do curto prazo $^{3}$.

\footnotetext{
${ }^{3}$ Além de Richard Sennett, Zygmunt Bauman é um dos mais atentos analistas do problema da instabilidade. Para Bauman, assim como a acumulação não afeta apenas a ordem econômica (como mostra a ética do trabalho-poupança), também sob o domínio de uma mentalidade organizada segundo o pensamento de curto prazo, a provisoriedade se espalha e cria níveis correlacionados com repercussões pessoais seríssimas: "Os compromissos (contratos de emprego, acordos de casamentos, arranjos para 'viver juntos') são assumidos tendo-se em mente uma 'opção de cancelamento', sendo considerados mais desejáveis e de maior qualidade segundo a firmeza de suas cláusulas 'de desfazimento'. Em outras palavras, está claro desde o início que o depósito de lixo será de fato, tal como deveria e como tende a ser, seu derradeiro destino. A partir do momento em que nascem, os compromissos são vistos e tratados como refugo em potencial. A fragilidade (do tipo biodegradável) é, portanto, vista como uma vantagem deles. É fácil esquecer que os
} 
O princípio da satisfação adiada, como fundamento axiológico da vida de trabalho segundo projetos de longo prazo e antiga base de sustentação do capitalismo, tem de perder o valor num regime cujas instituições mudam rapidamente. A flexibilização do trabalho, com todas as implicações que isso comporta, é um fenômeno emergente de codificação ética própria com novas convicções sobre mérito e talento, que traduzem o colapso e mesmo a inversão da antiga ética do trabalho com ênfase sobre a vocação, a competência, as habilidades e as realizações de longo prazo (ascetismo leigo).

O fenômeno da flexibilização implica portanto o fim do trabalho como conjunto de práticas que podiam sustentar o sistema valorativo tradicional do capitalismo, no qual "o indivíduo colhido nos labores do ascetismo leigo lutando para adquirir controle sobre si mesmo [...], realizava a teologia do indivíduo de Lutero num mundo secular." (SENNETT, 2011, p. 130). Isso significa que os valores do trabalho que dependiam de um vigoroso senso de caráter pessoal, alicerçado sobre o uso autodisciplinado do tempo, com ênfase em práticas voluntárias ou auto impostas, estão agora mais dependentes de qualidades flutuantes do indivíduo flexível; o indivíduo adaptável às circunstâncias essencialmente cambiantes da economia global politicamente emancipada.

Ao contrário da ética precedente, a ética do novo trabalho tem as raízes lançadas num ordenamento econômico inteiramente voltado para o presente, em cujo contexto as virtudes da vida de trabalho se definem mais em termos de aptidões potenciais instáveis (que incorporam a "adaptabilidade" ideal da nova economia), e de empenhos aparentemente colaborativos (claramente situados na superfície da experiência profissional), que em termos de capacidades e talentos individuais fundados na autodisciplina, na vocação e na experiência acumulada. Daí que a "superficialidade degradante", a ausência de objetivos duráveis somada à ênfase sobre qualidade fugidias do indivíduo flexível, seja para Sennett o signo do novo trabalho e dos valores que o orientam. O destaque sobre a cooperatividade e a adaptabilidade às circunstâncias, típicas do trabalho em equipe, traduzem os valores da ética do trabalho que se situam na superfície, vale dizer, na dimensão mais rasa da experiência profissional.

Esses valores, como os da antiga ética do trabalho, estipulam igualmente que "só um tipo de ser humano é capaz de prosperar em

compromissos que criam vínculos foram procurados em primeiro lugar, e continuam a ser procurados, para se eliminar aquela desorientadora e aterrorizante fragilidade da existência humana. Esvaziada da confiança, saturada de suspeita, a vida é assaltada por antinomias e ambiguidades que ela não pode resolver. À espera de ir em frente sob o signo do lixo, ela cai do desapontamento para a frustração, aterrissando a cada vez no próprio ponto de que desejaria escapar quando começou sua jornada exploratória. Uma vida assim vivida deixa atrás de si uma série de relacionamentos frustres e abandonados - o refugo das condições globais de terra de fronteira, notória por reclassificar a confiança como um signo de ingenuidade e uma armadilha para o inábil e o simplório.” (BAUMAN, 2004a, p. 115-6) 
condições sociais instáveis e fragmentárias" (SENNETT, 2006, p. 13). Mas, ao contrário do que se passa no regime em que prevalece o imperativo da procrastinação, a individualidade ideal do regime flexível deve antes de tudo saber se ajustar à organização do trabalho segundo projetos de curto prazo, assim como deve estar permanentemente disposta a mudar não apenas de uma tarefa para outra, mas também de um emprego a outro e de um lugar a outro. No limite, o indivíduo ideal deve estar disponível para improvisar sua própria narrativa de vida e se desvencilhar das experiências precedentes.

Há que se destacar ainda, no curso da reflexões de Richard Sennett, que no domínio da flexibilidade esse desafio impõe ainda problemas incontornáveis ao desenvolvimento do talento profissional como ele foi tradicionalmente admitido, já que o fluxo constante das exigências renovadas impele à necessidade contínua de descobrir e fazer aflorar as capacidades potenciais de breve vida útil. O domínio da flexibilidade que avança sobre o mundo do trabalho combate o talento e o mérito pressupostos na determinação de aprender a fazer bem apenas uma coisa. Este compromisso que é o espírito típico do artesanato, e a substância mesma da antiga noção de vocação profissional, é algo que no domínio do mundo flexível tende a revelar-se economicamente destrutivo. Razão porque talento e mérito têm de ser redefinidos sob condições instáveis. É neste contexto que o ideal do artesanato corporificado na perícia cede lugar às habilidades potenciais do indivíduo flexível, e o valor da capacidade de adaptação às circunstâncias sobrepuja o mérito das realizações passadas, que doravante devem ser deixadas para trás.

\section{Da ética da procrastinação ao princípio da satisfação imediata}

Apesar das notáveis mudanças operadas sobre o mundo do trabalho, a mais radical das transformações já registradas no capitalismo passa antes de tudo pela ênfase inusitada sobre a capacidade que os rendimentos do trabalho asseguram: a capacidade de consumo. Chamamos de revolução copernicana do capitalismo a virada extraordinária que, no interior deste sistema econômico, substitui o imperativo da satisfação adiada e as realizações a longo prazo pelo princípio consumista da satisfação imediata e renovada; a frugalidade pela prodigalidade, o ascetismo pelo gasto dispendioso, as práticas compulsórias de poupança e postergação pelo desejo incontido de felicidade aqui e agora perseguido via consumo.

Se a questão do consumo leva-nos de fato ao cerne da nova economia, deste outro lado da análise do trabalho, a saber, o destino atualmente mais comum de seus rendimentos, a palavra consumo tem prioridade sobre flexibilidade como qualificativo maior da presente economia. Para o nosso propósito importa mostrar que a era do crédito, na medida em que coroa a nova economia de consumo, mais do que desferir os 
derradeiros golpes na antiga ética da procrastinação a subverte, ou seja, coloca seu princípio de base de pernas para o ar.

Que no âmbito do consumo a economia flexível responde de fato pela inversão das exortações com que Benjamin Franklin (o tipo exemplar da velha ética do trabalho), recomendava a contrição material neste mundo como padrão de excelência de uma vida conduzida segundo os limites ditados pelo dever de poupar, pode ser evidenciado pelo fato de que o consumo elevado foi a um só tempo alçado à condição de vida desejável e, principalmente, fim legítimo da nova ordem econômica.

Em nosso contexto o decisivo é que, nos Estados Unidos dos anos de 1950 - nascedouro e fonte de propagação do novo sistema econômico -, "o maior instrumento de destruição da ética protestante foi a invenção do crédito." Pois como Daniel Bell observou em seu estudo acerca do entrechoque dos valores por ele examinado, "antes era preciso primeiro economizar para depois comprar. Mas com o crédito tornou-se possível satisfazer todos os desejos' (BELL, 1994, p. 223). Portanto, mais do que qualquer outro expediente, a invenção capitalista do crédito manifesta a extraordinária inflexão cultural, mas também o embate de princípios norteadores da vida social, provocados por esse sistema econômico no fenômeno que Daniel Bell registou em As contradições culturais do capitalismo.

É bem verdade portanto que a grande transformação cultural da sociedade moderna mais recente se deve primeiramente à promoção do consumo massivo, que nos EUA é um evento deflagrado já no decênio de 1920. Isso graças a um processo no qual "os luxos do passados são constantemente redefinidos como necessidades, de modo que", a partir de então, "chega a parecer incrível que um objeto ordinário tenha sido alguma vez considerado fora de alcance do homem comum" (BELL, 1994, p. 73). A ascensão do consumo massivo significa assim a difusão crescente do que antes era considerado luxo às classes média e baixa.

Ocorre porém que em virtude da renda de tais classes, essa rápida disseminação teria sido particularmente inviável sem a invenção do crédito, isto é, a disseminação da compra a prazo que acima de qualquer outro fator do processo de transformação cultural em curso, exige não tanto a ruptura, quanto a própria inversão da ética protestante. É próprio desta transformação cultural simbolizada pela prática de financiamento do consumo, que a palavra crédito assuma um sentido econômico acentuadamente distinto do que tinha até momento. $\mathrm{O}$ enlace econômico entre crédito e consumo aponta para o próprio cerne da revolução capitalista.

Para o espírito do capitalismo que coordenava as ações do ascetismo leigo de Benjamin Franklin, crédito significava antes de tudo aplicação ou investimento, a saber, um tipo de oportunidade para multiplicar dinheiro, que por sua vez, como disse o próprio Franklin, "é de natureza prolífica, 
procriativa". É natural sob a perspectiva de qualquer fase do capitalismo (portanto não só o dos dias de Franklin) que o dinheiro seja visto como algo que está sempre prenhe de mais dinheiro. Mas é um traço particularmente típico da antiga ética protestante, comprometida com a postergação, conceber o crédito como a possibilidade de - a partir de um empréstimo e mediante juros - obter ou explorar e aumentar para o futuro os rendimentos da soma conferida ou recebida de outrem sob confiança e por tempo determinado. Daí o sentido da exortação de Franklin:

Lembra-te de que o crédito é dinheiro. Se uma homem permite que seu dinheiro permanece em minhas mãos por mais tempo do que é devido, ele me dá os juros, ou o quanto eu puder fazer com ele durante este tempo. Isso atinge uma soma considerável quando um homem tiver um bom e amplo crédito, e fizer um bom uso dele." (FRANKLIN apud WEBER, 2008, p. 26)

Com o intuito de assegurar as máximas qualidades procriativas do dinheiro, que neste sistema econômico convergia com a proficiência numa vocação para a qual o indivíduo se sentia com obrigações éticas, Franklin recomendava um extremo zelo em resguardar os mais ínfimos sinais que a conduta pessoal pudesse oferecer à confiança. Esta é a palavra que para a mentalidade utilitarista dessa "filosofia da avareza" (Weber), designava a qualidade humana fundamental para quem busca ter um amplo crédito e a partir disso fazer mais dinheiro. Não é outro o sentido da advertência abaixo cita por Max Weber:

\begin{abstract}
As mais insignificantes ações que afetem o crédito de um homem dever ser consideradas. $\mathrm{O}$ som de teu martelo às cinco da manhã, ou às oito da noite, ouvido por um credor o fará conceder-te seis meses a mais de crédito; ele procurará, porém, por seu dinheiro no dia seguinte se te vir em uma mesa de bilhar ou escutar tua voz em uma taverna quando deverias estar no trabalho; exigi-lo-á de ti antes de que possas dispor dele, todo de uma vez. (FRANKLIN apud WEBER, 2008, p. 26)
\end{abstract}

Há ainda outro aspecto decisivo que nos faz reconhecer uma ênfase peculiar sobre o conceito de crédito, conceito este que no fim das contas reflete os valores da chamada fase heroica do capitalismo. A frugalidade, a autonegação e a parcimônia são as virtudes cardeais de quem possuindo crédito, o emprega apenas em vista da qualidade prolífica do dinheiro e da poupança compulsória que dirigem a ética no antigo mundo do trabalho. $\mathrm{O}$ que a exortação supracitada não nos permite vislumbrar senão indistintamente, como pano de fundo da cena em que protagonizam os esforços laboriosos de quem almeja ser digno de crédito, é diretamente expresso na passagem a seguir, que tomo novamente da leitura Weber: 


\begin{abstract}
Guarda-te de pensar que tens tudo o que possuis e de viver de acordo com isto. Este é um erro que comentem muitos que têm crédito. Para evita-lo, mantém por algum tempo a conta exata de tuas despesas e da tua receita. Se tiveres o cuidado de, inicialmente, registrar os detalhes isso terá o seguinte efeito salutar: descobrirás como as mínimas e insignificantes despesas se amealham em grandes somas, e discernirás o que poderia ter sido e o que poderá ser economizado para o futuro, sem grandes inconvenientes. (FRANKLIN apud WEBER, 2001, p. 26)
\end{abstract}

A nova ênfase sobre o crédito põe às avessas a moral puritana do trabalho e, por consequência necessária, o destino de seus rendimentos. Pois o que agora está em questão no crédito é o encorajamento ao gasto, o aproveitamento da vida e a vazão dos impulsos e dos desejos, enfim, o financiamento do consumo. Com efeito, o sentido econômico hoje dominante da palavra crédito é absolutamente incompatível com a vida frugal que a ética precedente recomendava como dupla condição para obter crédito e dele fazer um uso rentável em vista do futuro. A não ser pela satisfação imediata do desejo que o crédito dispensa da espera, e também pelas dívidas a longo prazo contraídas pelo indivíduo, a palavra crédito já não resguarda qualquer relação com o futuro, ou ainda, se resguarda, essa relação entre crédito e futuro tem um sentido estritamente negativo. Haja visto que o aspecto característico do crédito é a desqualificação da espera e da gratificação postergada. Sua verdadeira afinidade é com o momento presente que a contração de crédito incita a aproveitar de modo obstinado. Neste novo enfoque, como disse Bell, "a artimanha da venda a prazo foi evitar a palavra dívida e destacar a palavra crédito". (BELL, 1994, p. 76).

Em completo divórcio com o autocontrole da poupança e com a ética da satisfação adiada, que doravante escasseiam-se cada dia um pouco mais, o crédito agora designa prioritariamente o emprego dos rendimentos no sentido inverso de consumo, satisfação imediata, dispêndio e dilapidação. Ele é portanto um fenômeno sintomático do nosso tempo, já que desde o princípio a economia liderada pelo consumo é simultaneamente operada pelo crédito. No espírito oposto às exortações do homem-poupança tipificado na figura de Benjamin Franklin, as mais significativas exortações que agora pregam a norma social da vida a crédito, a saber, da vida consagrada ao consumo ou a própria estimulação do homem-consumidor, podem ser sumarizadas em duas exortações inteiramente confluentes: "guarda-te de esperar inutilmente obter os rendimentos que somente a longo prazo poderiam satisfazer os teus desejos", e "não se deve retardar as realizações dos desejos que o crédito permite satisfazer hoje."

De qualquer maneira, quando os cartões de crédito puseram essa "filosofia consumista ao alcance de um número crescente de indivíduos" (BAUMAN, 2011b, p. 32), restava ainda ao novo sistema econômico a tarefa de lidar com o impasse criado pela resistente cultura forjada na velha 
e agora ultrapassada ética da postergação, em que se fundava o espírito de poupança do capitalismo. Avaliada sob esta perspectiva, a venda a crédito, que segundo as pesquisas de Daniel Bell foi intermitentemente praticada nos Estados Unidos antes mesmo da Primeira Guerra Mundial, esteve inevitavelmente atrelada aos estigmas sociais da condição de pobreza dos que não se podiam permitir maiores gastos, ou daquela parte da classe média que se permitia a contração de dívidas para desfrutar a vida acima dos próprios meios. Este julgamento depreciativo, do sentido agora dominante conferido ao crédito, é em si mesmo o reflexo do contexto social em que "ser moral significava ser laborioso e econômico" (BELL, 1994, p. 76).

A vida a crédito, ou a adesão universal da venda a prazo, é um fenômeno social que em grande medida envolve a internalização das novas normas econômicas para o comportamento e a vida desejáveis. "Comprar a crédito e viver em dívida se tornam normas [...] na modalidade da vida de consumidor." (BAUMAN, 2004a, p. 137). O que essa adesão mais supõe, na medida em que exige certos esforços alquimistas para mudar em opróbio o princípio ético da gratificação postergada, é a propaganda; a onipresente estratégia moderna da oferta. Uma estratégia cujo impacto social e foça de obstinação têm se mostrado determinantes para demover as sólidas convicções éticas que cimentaram aquele comportamento econômico que Weber mostrou estar desde o início ancorado em um princípio transcendente ${ }^{4}$.

Não obstante a profunda radicação da moral ascética, as tecnologias ubíquas da publicidade foram decisivas na instalação da nova significação social do consumo. "Desculpabilizando o ato de compra, a publicidade desculpabilizou o fenômeno do consumo, aliviando-o de uma certa gravidade contemporânea da ética da poupança.” (LIPOVETSKY, 2009b, p. 229). Como quer que se compreenda os dispositivos publicitários de mobilização ao crédito e à vida consagrada ao consumo, não se pode negar, como disse Gilles Lipovetsky, que a publicidade é uma "estocástica da estimulação".

Mas ainda que situada no âmbito da comunicação de massa, estrategicamente endereça à liberação dos desejos e à promoção do tipo de felicidade que à ética passada coube reprimir (a gratificação imediata), a mensagem publicitária não é a administração benévola de homens que em princípio parece ser. Antes é mais uma dentre as formas tipicamente modernas de dominação burocrática e racionalização do poder. A despeito

\footnotetext{
4 "Se se pensa no impacto social da propaganda, sua consequência mais imediata, embora geralmente inadvertida, foi transformar o centro das cidades. Ao refazer a topografia física, e substituir os velhos duomos, os edifícios municipais e as torres dos palácios, a propaganda colocou uma 'maraca de ferro quente' na crista de nossa civilização. É o signo dos bens materiais, o modelo de novos estilos de vida, o arauto de novos valores.” (BELL, 1994, p. 75)
} 
da suavidade de seus métodos que (em contraste com as instituições disciplinares examinadas por Michel Foucault) sempre abrem margem para a personalidade escapar à sua ação persuasiva, a eficiência da publicidade também se mede pela capacidade de guiar de fora os comportamentos dominantes da vida social. De penetrar até os menores interstícios da sociedade e recompô-los segundo a nova ordem econômica consumista em nome da qual atua.

É certo que o indivíduo se desonera de estruturas de sustento e vínculos tradicionais, mas recebe em troca as pressões do mercado de trabalho, de uma subsistência baseada no consumo e das padronizações e controles contidos em âmbitos. Em lugar de vínculos e formações sociais tradicionais (classes sociais, família nuclear), entram em cena instâncias e instituições secundárias, que imprimem sua marca na trajetória do indivíduo e atuam no sentido contrário do arbítrio individual que se realiza sob a forma de consciência, tornando-o um joguete de modas, circunstâncias, conjunturas e mercados. (BECK, 2010, p. 194)

Particularmente sob a ação da publicidade, no que nela há de determinante para a promoção dos novos valores sociais, "o consumidor interioriza, no próprio movimento do consumo, a instância social e suas normas." (BAUDRILLARD, 2011, p. 323). Esta é, seguramente, para Jean Baudrillard, uma das significações fundamentais da publicidade. A publicidade é o próprio arauto dos novos valores econômicos liderados pelo consumo. E isso é o mesmo que dizer que sob tais condições modernas, a função das sofisticadas técnicas da oferta é criar a demanda. Naturalmente, este princípio é do mesmo modo válido para o próprio crédito.

Pela promoção do crédito e a aceitação dos novos valores sociais de base econômica (que este fenômeno supõe), o consumo massivo e um elevado nível de vida foram efetivamente alçados a fim legítimo e principal da organização econômica. Essa revolução copernicana que, na constelação capitalista, substitui a procrastinação pelo princípio oposto da satisfação imediata, o ascetismo leigo pelo consumo, se desdobra finalmente na concepção e na relação com a riqueza e com a prosperidade econômica, que são também inteiramente novas.

A bem da verdade, o enriquecimento admitido como meta em sua natureza processual, ainda faz do capitalismo um sistema econômico estranhamente privado de consumações. Um tipo de ordenamento econômico que Aristóteles seguramente teria classificado como o resultado de uma terrível confusão mental inversora dos sinais elementares do bem viver, na medida em que toma como fim verdadeiro aquela ordem de coisas que, a despeito de toda a facilidade por elas usufruídas, não passam de meios para sobrevivência. Em todo caso, esta regularidade que põe em acordo dois momentos distintos da ordem econômica capitalista não deixa 
de ser em certo sentido insidiosa. Há que se considerar que a consumação do crédito, enquanto responde pela consolidação da órbita social em torno do consumo, é um evento coevo ao advento de um novo parâmetro para o trato com a riqueza e com a prosperidade.

Num cenário de novos valores econômicos em que o padrão objetivo exterior aos próprios desejos definha como critério de valoração do artifício humano; em que o valor e a solidez das objetivações são sobrepostas pelos princípios da sobrevivência, do gozo e da satisfação renovada (que são critérios eminentemente subjetivos de avaliação do mundo elevados ao primeiro plano pela nova economia), em um tal cenário os sinais da prosperidade econômica terminam por se deslocar das coisas para o próprio indivíduo. E para o indivíduo exclusivamente concebido como sujeito de consumo. De fato, sob a perspectiva da individualidade idealizada pela economia de consumo.

\footnotetext{
Um carro se converte no signo da 'boa vida' bem vivida, e o atrativo da sedução se generaliza. Uma economia de consumo, sem dúvidas, encontra sua realidade nas aparências. O que se exibe, o que se mostra, é um signo da conquista. Prosperar já não é questão de ascender em uma escala social, como foi no superado século XIX, mas adotar um estilo específico de vida um clube rural, ostentação, viagens, 'hobbies' - que o distinga como membro de uma comunidade de consumo. (BELL, 1994, p. 75)
}

Os sinais característicos da prosperidade econômica de nenhum modo se prendem hoje às coisas como portadoras de qualidades objetivas. Mas é igualmente certo que a equação ética que equiparava as posses com o reflexo das virtudes morais do "ascetismo leigo" (do indivíduo que prova seu valor moral pelo trabalho árduo e pela disciplina auto imposta), não reconheceu a objetividade das coisas senão como um aspecto incidental, um traço absolutamente acessório ou secundário da riqueza. Em si mesma perseguida como processo infindável num tempo em que a prosperidade econômica, em flagrante contraste com as satisfações pessoais, ainda era aferida exclusivamente pelo mero acúmulo de coisas.

Este acúmulo de bens, em que pese o resignado alento ético da postergação (que em princípio sacrificava o presente em nome de uma satisfação futura), era no fundo a finalidade derradeira e auto justificada do sistema econômico profundamente enredado nas próprias práticas de poupança. Pois a verdade é que o homem-poupança modelado pelo ascetismo intramundano, condicionado a viver o futuro em cada momento do presente, "só gasta o mínimo necessário para chegar ao próximo instante e assim para sempre." (LIMA, 2011, p. 60)

O compulsório e incontrolado adiamento da satisfação, em virtude do qual as motivadoras esperanças de recompensas no futuro tendiam a não se consumar (esta espécie de "fraude" que Max Weber via no ascetismo 
leigo), era na verdade o mais autêntico e recôndito vestígio de uma ética econômica que embora laica, fora originalmente fundada sobre o princípio transcendente que reconhecia na riqueza um sinal inconfundível da eleição divina. $\mathrm{O}$ trabalho como virtude e o princípio transcendente do enriquecimento pelo enriquecimento, portanto como valores em si independente de gozos e desfrutes pessoais, são os principais pontos de intersecção entre o protestantismo e o moderno sistema econômico.

Esse ascetismo leigo assim constituído e exemplarmente manifesto nas aferradas e intermináveis práticas de poupança de Benjamin Franklin, é a própria marca de ferro quente da ética protestante sobre o espírito do capitalismo. Nesse sistema de valores as qualidades morais espelhadas na riqueza serão tanto mais ostensivas quanto mais rigorosas e intransigentes forem as práticas de autonegação de uma vida em que o indivíduo (consoante à exortação de Franklin e cioso de um forte compromisso com o futuro), se guarda de pensar que tem tudo o que possui e de viver de acordo com isso.

A promoção do crédito e a consolidação de uma cultura correlata ao sistema econômico de consumo, sepultaram os derradeiros resquícios dessa moral econômica sustentada em empreendimentos de longo prazo, dado que seu aspecto marcante consiste em virar do avesso, isto é, transmutar em opróbio o imperativo ético-econômico da autonegação em vista da poupança ${ }^{5}$. Neste caso, "a síndrome da cultura consumista consiste, acima de tudo, na negação enfática da virtude da procrastinação e da possível vantagem de se retardar a satisfação - esses dois pilares axiológicos da sociedade de produtores governada pela síndrome produtivista" (BAUMAN, 2008, p. 111).

Portanto, o desvio drástico e seminal que desloca o capitalismo flexível para a nova órbita econômica das realizações renovadas e imediatas da vida consagrada ao consumo, em manifesta oposição às aspirações de longo prazo do homem-poupança, é a revogação dos valores vinculados à duração e à estabilidade subjacentes à antiga ética econômica. Em conexão direta com a hipertrofia da produção econômica que caracteriza as sociedades emergentes, o consumismo atua como um dos mais destacados agente de promoção da fluidez em uma economia que nega e milita contra toda ordem estável.

Indicamos acima que pela desqualificação dos valores ligados à duração e à estabilidade também na ordem do trabalho, a nova economia pretende elevar à condição de um plano de vida coerente (mas também à

\footnotetext{
${ }^{5}$ Nas sociedades de consumo "esperar é uma vergonha, e a vergonha de esperar recai sobre aquele que espera. A espera é algo de que se deve envergonhar porque pode ser observada e tomada como prova de indolência ou baixo status, vista como sintoma de rejeição e sinal de exclusão. A suspeita de que não se é muito procurado, intuição que nunca está longe demais do nível da consciência, agora emerge à superfície e provoca inúmeras ruminações [...]." (BAUMAN, 2004a, p. 135)
} 
condição de uma virtude necessária ao trabalhador moderno), a disposição de ser "flexível"; de assumir e se ajustar à contingência e a instabilidade que a própria economia encerra. Ceder à mutabilidade estrutural da nova economia é o único, vago e incerto "plano estratégico" para o trabalho nos setores de ponta do capitalismo flexível. Instabilidade, descontrole e risco definem hoje as condições fundamentais de crescimento da riqueza social num sistema econômico presidido pelo "capital impaciente", isto é, avesso a compromissos, realizações e sobretudo a rendimentos de longo prazo.

$\mathrm{O}$ acordo de fundo entre as condições do trabalho flexível e o sistema normativo econômico mais recente, que organiza a vida social em torno do consumo, é a militância contra toda forma de estabilidade e/ou circunspecção a longo prazo, quer no domínio das ocupações humanas, quer no âmbito da relação com o mundo das coisas ${ }^{6}$.

No contexto de instabilidade, alienação do mundo e esgotamento de todo resquício de transcendência em que se forjam indivíduos particularmente auto referidos ou, nas palavras de Hannah Arendt, indivíduos "arremessados para dentro de si" (ARENDT, 2010, p. 316), a prosperidade econômica que não se traduz em fruição é motivo social para vergonha e objeto de sérias preocupações pessoais. Preocupações que inclusive inspiram uma abordagem terapêutica em psicanálise: "antes a gratificação dos impulsos proibidos despertava sentimentos de culpa, agora o não desfrute diminui a própria estima." (WOLFENSTEIN apud BELL, 1994, p. 77).

Neste caso, o consumismo é o próprio signo da vida bem-vivida. Estar privado dele, para os padrões vigentes de normalidade, só pode resultar do estado involuntário e indesejável de marginalidade social. "O consumo de bens", como firmou Galbraith, se torna "a primeira medida de realização social” (GALBREITH apud LIMA, 2011). Por isso, os novos tempos que a consolidação do crédito anuncia transformaram em profundidade o cenário econômico e a própria cultura ao substituir o indivíduo autodirigido pelo indivíduo autorreferido, as práticas compulsivas

\footnotetext{
${ }^{6}$ Desde Pierre Bourdieu sabemos que a sociedade de consumo, na qual a liberação dos impulsos assume o lugar do recalque, também em grande medida substitui o controle disciplinar (examinado por Michel Foucault) pelas técnicas de sedução. Em Felicidade paradoxal Gilles Lipovetsky procura mostrar que estas técnicas foram particularmente entrevistas pelo "grande magazine", que "não vende apenas mercadorias, [mas também] consagra-se a estimular a necessidade de consumir, a excitar o gosto pelas novidades e pela moda por meio de estratégias de sedução que prefiguram as técnicas modernas do marketing. Ao impressionar a imaginação, despertar o desejo, apresentar a compra como um prazer, os grandes magazines foram, com a publicidade, os principais instrumentos da elevação do consumo a arte de viver e emblema da felicidade moderna. Enquanto os grandes magazines trabalhavam em desculpabilizar o ato de compra, os shoppings, o "olhar vitrines", tornaram-se uma maneira de ocupar o tempo, um estilo de vida das classes médias." (LIPOVETSKY, 2007a, p. 31).
} 
de contrição e economia pelos hábitos incontidos de consumo, o homempoupança pelo homem-consumo.

A trivialidade cotidiana envolta na expressão "sociedade de consumidores", sobretudo por obra de sua recorrente veiculação publicitária e midiática, mas também em virtude de certos apelos políticos, é, no mais das vezes, capciosa. Sociedade de consumidores é uma expressão que conceitualmente oculta os mecanismos de controle e, sobretudo, as normais que regem o comportamento social típicos de nossa época ${ }^{7}$.

Que o consumismo defina a norma social para o comportamento econômico que hoje é até mesmo politicamente desejável, é um fato ostensivamente demonstrado na análise de Zygmunt Bauman à primeira e em princípio estranha declaração do então presidente dos Estados Unidos, George W. Bush, aos americanos logo após os ataques de 11 de setembro de 2001. No breve e significativo capítulo "Consumismo é mais que consumo", o décimo sétimo do livro 44 cartas do mundo líquido moderno, Bauman afirma o seguinte:

[...] a primeira mensagem do presidente Georg W. Bush aos americanos chocados e estupefatos diante do desmoronamento das Torres Gêmeas emblemáticas da supremacia mundial do Estados Unidos, atravessadas por aviões pilotados por terroristas, foi para que todos 'votassem às compras'. A intensão da mensagem era conclamar os americanos a retomar a vida normal." (BAUMAN, 2011b, p. 84)

A conclamação política ao consumo no "voltemos às compras", convoca para o esforço de retomada das atividades rotineiras, às práticas que definem a regra geral e a normalidade social do cotidiano. Não há portanto quaisquer motivos que nos leve a duvidar que "bem antes do ataque inimigo, os americanos já deviam estar convencidos de que ir às compras era a maneira, talvez a única e com certeza a principal, de curar todas as aflições, repelir e espantar todas as ameaças, reparar todas as falhas" (BAUMAN, 2011b, p. 83).

Mais do que simplesmente reduzir um fenômeno excepcionalmente aterrador, estonteante e profundamente maligno à condição de interrupção

\footnotetext{
7 “A principal mensagem dos mercados consumidores, plena e verdadeiramente sua metamensagem (a mensagem que sustenta e confere significado a todas as outras), é a indignidade de todo e qualquer desconforto e inconveniente. Uma postergação da recompensa, a complexidade de uma tarefa que transcende as habilidades, as ferramentas e/ou recursos já possuídos por seus executores, e uma combinação dos dois (a necessidade de se envolver numa formação e num trabalho de longo prazo para tornar viável a gratificação do desejo) são condenadas a priori como injustificadas e injustificáveis, e sobretudo inúteis e evitáveis. É do mergulho nessa mensagem e da absorção dela que os mercados consumidores extraem a maioria de seus poderes de sedução." (BAUMAN, 2010b, p. 193)
} 
momentânea, embora dramática de certos engajamentos regulares, a normalidade da convocação proclamada de dentro desse evento-limite à vida civilizada (o terrorismo), denuncia o teor do compromisso, tanto social quanto político, com a economia de consumo. Não fosse pelo fato de encarnar a própria normalidade da vida, voltar às compras imediatamente após os ataques de 11 de setembro (como recomendava George W. Bush), seria, para dizer o mínimo, uma grave violação ao luto nacional. A conclamação acima referida somente poderia chocar aqueles poucos em cujos ouvidos ela não encontrasse eco e, assim, não fizesse sentido. Portanto, a despeito da estranheza que aquela declaração contém em princípio, não deve suscitar surpresa o fato de que ela não tenha provocado espanto e nem mesmo o menor rumor. $\mathrm{O}$ consumismo era já não apenas a norma da vida social, como o traço mais emblemático da arte de viver, da felicidade em sua concepção inteiramente moderna.

Em Vida para consumo Bauman afirmou que "o consumismo chega quando o consumo assume o papel-chave que na sociedade de produtores era exercido pelo trabalho" (BAUMAN, 2008, p. 41). Em outras palavras, o consumo é o veredicto ou a própria condição inegociável da vida em sua dimensão biológica, enquanto o consumismo é o produto historicamente localizável de um certo sistema normativo para organização da vida em sociedade. Consumismo transmuta em "forma de organização" da existência humana a exigência básica da vida em sua acepção elementar. A palavra consumismo traduz assim a tendência em fazer do consumo o centro da órbita social; a admissão desta atividade natural como o aspecto central e o denominador comum de todos os interesses e envolvimentos humanos.

Consumismo, em última análise, é a denominação para o fato de que o consumo passou a ser "especialmente importante, senão central para a vida da maioria das pessoas, o verdadeiro propósito da existência". (CAMPBELL apud BAUMAN, 2002, p. 104). Obviamente o consumismo assim compreendido não designa uma forma específica do convívio humano, já que o consumo tem uma radicação biológica comum e incontornável à qualquer vivente. De qualquer maneira, enquanto "forma de organização" da vida coletiva cujo aspecto característico foi sempre aspirar a algo que se julgava mais importante que o próprio consumo (a liberdade política, a salvação da alma, a perícia, o acúmulo de riqueza), trata-se de um acontecimento realmente novo. Isso considerando que nesse domínio o consumo é não apenas e inegociavelmente a conditio sine qua non, quanto a própria conditio per qua de todo o arranjo humano para a vida coletiva.

Esse estado de coisas em que a política e a sociedade "interpela seus membros (ou seja, dirige-se a eles, os saúda, apela a eles, questiona-os, mas também os interrompe e 'irrompe sobre' eles) basicamente na condição de consumidores" (BAUMAN, 2008, p. 70. Ênfase do autor) delimita o ordenamento em que o consumismo é a norma social. Em semelhante condição o consumo é elevado à principal conduta a ser incentivada e 
esperada como digna de apreço ${ }^{8}$. Uma vez que o consumo seja alçado à condição de meta principal e critério de cuja perspectiva se julga o sentido, a relevância e a adequação dos empreendimentos humanos, as demais atividades são desqualificadas como epifenômenos de tal escopo que a tudo subordina.

Se a vida para consumo elege essa atividade como a principal, ao mesmo tempo em que rebaixa todos os outros aspectos a um plano inferior, derivado, secundário, seu mais autêntico e notório significado é destacar e, por isso tendencialmente reduzir os seres humanos à condição natural de consumidores. A despeito do uso corriqueiramente descuidado ou ingênuo, este é, aliás, o registro em nada epidérmico de expressões como "sociedade de consumo" e "sociedade de consumidores".

Quando não consideradas em suas peculiaridades, essas simples definições do perfil das sociedades hodiernas tendem a escamotear a transformação profunda que conferiu ao novo subsistema econômico o poder de reconfigurar as formas humanas de convivência, graças à consolidação de uma mentalidade de curto prazo ajustada ao sistema normativo da economia flexível.

No fluxo dessa tendência há outro evento destacado para o qual não pudemos aqui senão sinalizar. Trata-se das repercussões políticas do novo sistema econômico que, entre outras coisas, se desdobram na redistribuição de poder entre as instituições políticas e as pressões da economia flexível. Em todo caso, independente do ângulo de que se contemple a saga da economia flexível (do mundo do trabalho, dos valores sociais ou de suas mais recentes repercussões políticas), a instabilidade, a contingência e os riscos oriundos de uma nova e poderosa economia que se emancipou, estabelecem cercos realmente inusitados e decisivos à vida social.

\section{Referência bibliográfica}

ARENDT, Hannah. A condição humana. 11 ed. Rio de Janeiro: Forense Universitária, 2010.

\footnotetext{
8 "O indivíduo [agora] serve o sistema industrial, não para abastecê-lo com a poupança e o capital dele resultante; ele o serve pelo consumo de seus produtos. Em nenhum outro assunto, religioso, político ou moral, está a comunidade tão elaborada, perita e dispendiosamente instruída. Especificamente de modo paralelo à produção de bens, são feitos esforços enérgicos e não menos importantes para garantir o seu uso. Este esforços enfatizam a saúde, a beleza, a aceitação social, o sucesso sexual - a felicidade, em resumo que resultarão da posse e do uso de um determinado produto. Esta comunicação, combinada diariamente com o esforço em prol de inumeráveis outros produtos, torna-se, no conjunto, um argumento ininterrupto de vantagens do consumo. Por sua vez, inevitavelmente, este fato afeta os valores sociais. O padrão de vida de uma família torna-se a produção e, pari passu, o consumo de bens sejam a primeira medida de realização social." (GALBRAITH apud LIMA, 2011, p. 66)
} 
Trabalho, obra, ação. Cadernos de Ética e Filosofia Política, 7, p. 187-213. 2006c.

ARISTÓTELES. Política. São Paulo: Editora Nova Cultural, 2000.

BAUDRILLARD, Jean. Significado da publicidade. In: LIMA, Luiz Costa (Org.). Teoria da cultura de massa. 8 ed. São Paulo: Paz e Terra, 2011. p. 317-327 .

BAUMAN, Zygmunt. 44 Cartas do mundo líquido moderno. Rio de Janeiro: Jorge Zahar Editor, 2011b.

A ética é possível num mundo de consumidores? Rio de Janeiro: Jorge Zahar Editor, 2011a.

Capitalismo parasitário e outros temas contemporâneos. Rio

de Janeiro: Jorge Zahar Editor, 2010a.

Editor, 2009.

Confiança e medo na cidade. Rio de Janeiro: Jorge Zahar

Globalização - as consequências humanas. Rio de Janeiro: Jorge Zahar Editor, 1999.

. Modernidade líquida. Rio de Janeiro: Jorge Zahar Editor, 2001.

Vida a crédito. Rio de Janeiro: Jorge Zahar Editor, 2010b.

2004a.

- Vidas desperdiçadas. Rio de Janeiro: Jorge Zahar Editor,

- Vida para consumo - a transformação das pessoas em

mercadorias. Rio de

Janeiro: Jorge Zahar Editor, 2008.

BECK, Ulrich. Sociedade de risco. São Paulo: Editora 34, 2010.

BELL, Daniel. Las contradiciones culturales del capitalismo. México: Alianza Editorial, 1994.

LIPOVETSKY. Gilles. A cultura mundo. Resposta a uma sociedade desorientada. São Paulo: Companhia das Letras, 2011.

A era do efêmero. Ensaios sobre o individualismo contemporâneo. São Paulo: Manole, 2009a.

A tela global. Mídias culturais e cinema da era hipermoderna. Porto Alegre-RS: Editora Sulina, 2009c.

$2007 a$.

- Felicidade paradoxal. São Paulo: Companhia das Letras,

O império do efêmero. A moda e seus destinos nas sociedades modernas. São Paulo: Companhia de Bolso, 2009b.

. O luxo eterno. São Paulo: Companhia das Letras, 2008.

Os tempos hipermodernos. São Paulo: Barcarola, 2007b.

LIMA, Luiz Cota (Org.). Teoria da cultura de massa. 8 ed. São Paulo: Paz e terra, 2011.

SENNETT, Richard. A corrosão do caráter - consequências pessoais do trabalho no nova capitalismo. Rio de Janeiro, São Paulo: Editora Record, 2011. 
- A nova cultura do capitalismo. Rio de Janeiro, São Paulo: Editora Record, 2006.

WEBER, Marx. A ética protestante e o espírito do capitalismo. 2 ed. rev. São Paulo: Cengage Learning, 2001.

Conceitos básicos de sociologia. 4 ed. São Paulo: Centauro Editora, 2005. 